\title{
IDENTIFIKASI BENDA-BENDA BERSEJARAH DI MUSEUM PUSAKA NIAS
}

\author{
Oleh : \\ Arfan Diansyah \\ Winalni S. G. Harefa
}

\begin{abstract}
ABSTRAK
Penelitian ini bertujuan untuk mengetahui benda-benda yang menjadi koleksi Museum Pusaka Nias, mengetahui cara Museum Pusaka Nias memperoleh benda-benda pusaka Nias, dan mengetahui pengklasifikasian benda-benda pusaka Nias di Museum Pusaka Nias. Penelitian ini dilakukan di Museum Pusaka Nias yang beralamat di Jalan Yos Sudarso Nomor 134-A, Gunungsitoli, Kotamadya Gunungsitoli. Untuk memperoleh data-data tersebut, peneliti menggunakan metode penelitian lapangan dengan teknik pengumpulan data berupa observasi, wawancara, dan dokumentasi gambar. Penelitian ini juga menggunakan metode studi pustaka yang mencari dan mengumpulkan informasi dari berbagai literatur yang berkaitan dengan objek penelitian. Dari hasil penelitian yang telah dilakukan, diketahui bahwa Museum Pusaka Nias mengoleksi 6001 benda pusaka hasil kebudayaan masyarakat Nias. Benda-benda pusaka yang telah dikoleksi Museum Pusaka Nias diklasifikasikan berdasarkan bidang ilmu, seperti Etnografika, Arkeologika, Historika, Biologika, Numismatika (mata uang), Keramika, Dan Seni Rupa.
\end{abstract}

Kata Kunci : Identifikasi, Benda-Benda Bersejarah, Museum Pusaka Nias 


\section{PENDAHULUAN}

Pulau Nias merupakan bagian dari wilayah Provinsi Sumatera Utara. Terletak disebelah barat daya sekitar 85 mil laut dari Pelabuhan Sibolga. Sebagai bagian dari kepulauan Nias yang terdiri atas 132 buah pulau, Pulau Nias merupakan pulau terbesar dengan luas tidak kurang dari 5.449,70 $\mathrm{km}^{2}$.

Penduduk asli Pulau Nias itu menamakan diri mereka Ono Niha, artinya "anak manusia", dan menyebut pulau mereka Tano Niha, artinya "tanah manusia". Masyarakat Nias telah melahirkan sebuah perdaban yang tergolong sangat tua, unik, menarik, dan eksotik. Bukti-bukti peradaban tertua orang-orang Nias yaitu berkembangnya tradisi megalitik (red: megalit berarti batu besar). Hasil karya budaya itu sampai sekarang masih ditemui sisa-sisanya, seperti meja dan kursi batu, tugu-tugu, dan arca arwah serta omo hada (rumah adat) yang didirikan di atas batu-batu besar pipih dan dengan tiang-tiang kayu besar,yang dipenuhi dengan ukiran-ukiran kuno, hombo batu (lompat batu), dan maena baluse (tari perang).

Benda-benda pusaka Nias yang semakin langka tersebut kini sangat penting untuk dilestarikan. Pelestarian itu ditujukan kepada generasi sekarang dan berikutnya supaya mengetahui sejarah bangsanya dan tidak kehilangan jati diri. Dalam hal ini, peran museum sangat dibutuhkan. Museum sebagai sebuah lembaga tempat penyimpanan dan pameran benda-benda kuno yang mempunyai nilai dalam sejarah perkembangan manusia dan lingkungannya memiliki fungsi yang sangat mulia yang mampu mencegah masalah yang diuraikan diatas. Fungsi mulia tersebut yaitu pelanjutan nilai-nilai budaya bangsa kepada generasi muda agar mereka dapat menjadi seorang warga negara yang baik dan menjunjung tinggi nilai serta budaya bangsa dengan cara menyimpan, melindungi, mengembangkan, dan melestarikan benda-benda bersejarah yang sudah ditetapkan sebagai cagar budaya. 


\section{PEMBAHASAN}

\section{A. Sejarah Berdirinya Museum Pusaka Nias}

Museum Pusaka Nias didirikan Jalan Yos Sudarso No. 134-A Kelurahan Proklamasi Kecamatan Siantar Barat Kotamadya Gunungsitoli-Nias, propinsi Sumatera Utara. Museum Pusaka Nias terletak tidak jauh dari pusat kota Gunungsitoli. Berjarak sekitar 700 m dari pelabuhan Angin Gunungsitoli dapat ditempuh dengan berjalan kaki atau dengan kendaraan bermotor sekitar 3 menit. Sedangkan dari Bandar Udara Binaka berjarak sekitar $17 \mathrm{~km}$, dapat ditempuh sekitar 15 menit lewat jalur darat dengan menggunakan kendaraan bermotor.

Museum Pusaka Nias berada tepat di garis pantai. Luas area seluruh fasilitas di Museum Pusaka Nias adalah 2 ha. Adapun batas-batas wilayah Museum Pusaka Nias Yang berada di Gunungsitoli adalah sebagai berikut :

- Di Sebelah timur berbatasan langsung dengan Samudera Hindia.

- Sebelah utara berbatasan dengan Samudera Hindia.

- Sebelah barat berbatasan dengan Nias Utara.

- Sebelah selatan berbatasan dengan Kabupaten Nias.

Berdirinya Museum Pusaka Nias di Gunungsitoli merupakan buah dan hasil dari kerja keras Pastor Johannes Maria Hämmerle, OFM Cap. Diawal kedatangannya ke Pulau Nias pada tahun 1972, beliau tertarik dengan kebudayaan masyarakat yang ada di Pulau Nias. Beliau mulai mengumpulkan satu per satu benda-benda yang sudah langka dan kuno serta menulis kegunaan masing-masing benda. Beliau kemudian mengusulkan kepada Dewan Ordo Capusin Sibolga untuk mendirikan sebuah Museum.

Museum dapat didirikan oleh Instansi Pemerintah, Yayasan, atau Badan Usaha yang dibentuk berdasarkan ketentuan hukum yang berlaku di Indonesia, maka pendirian museum harus memiliki dasar hukum seperti Surat Keputusan bagi museum pemerintah dan akte notaris bagi museum yang diselenggarakan oleh swasta. Bila perseorangan berkeinginan untuk mendirikan museum, maka dia harus membentuk yayasan terlebih dahulu. 
Sehubungan dengan ketentuan diatas, setelah dikeluarkannya keputusan Kapitel Ordo Kapusin Provinsi Sibolga pada tgl. 28 Juli 1990, maka pada tanggal 19 April 1991 berdiri Yayasan Pusaka Nias dengan Badan Hukum Akte Notaris No. 4 Tahun 1991, dan telah didaftarkan di Pengadilan Negeri Gunungsitoli dengan No. 2/1991/YAS/PN-GS, tanggal 20 April 1991. Akta Notaris No. 4 Tahun 1991 telah diadakan perubahan sesuai dengan UU No. 16 tahun 2001 dan UU 28 Tahun 2004 tentang yayasan dengan Akta Notaris yang baru No. 6 Tahun 2008.

Yayasan Pusaka Nias sebuah lembaga non-profit yang secara khusus didirikan oleh Gereja Katolik cq. Ordo Kapusin Propinsi Sibolga merupakan sumbangan dan wujud keprihatinan Gereja terhadap masyarakat Nias yang didasarkan pada ajaran Konsili Vatikan II yang dituangkan dalam "Gaudium et Spes” yang isinya : bahwa tugas penggalian gereja adalah untuk memelihara, mengembangkan, mempromosikan, dan merevitalisasi budaya Nias sebagai landasan untuk mempertahankan dan menunjukkan identitas suku Nias di antara suku-suku bangsa di dunia.

Melalui sebuah rapat pleno Dewan Ordo, pada tahun 1993, Yayasan Pusaka Nias memutuskan untuk mendirikan gedung induk Museum Pusaka Nias di kota Gunungsitoli yang terdiri dari empat paviliun dan satu ruang tengah. Sedangkan gedung pendukung operasional museum selesai pada tahun 1995. Maka direncanakanlah sebuah acara peresmian museum oleh Ordo Kapusin pada 18 April 2005. Namun acara peresmian tersebut harus tertunda akibat terjadinya gempa yang melanda seluruh daratan Nias. Pada akhirnya, Museum Pusaka Nias diresmikan pada tanggal 18 November 2008 yang dihadiri oleh anggota Dewan Pertimbangan Presiden Letjen. TB. Silalahi dan Bupati Nias, Binahati B. Baeha, SH.

\section{B. Sarana dan Prasarana dalam Museum Pusaka Nias}

Museum Pusaka Nias merupakan museum lokal yang bersifat umum yang koleksinya terdiri dari kumpulan bukti material manusia dan lingkungannya yang berkaitan dengan berbagai cabang seni, disiplin ilmu dan teknologi yang diselenggarakan oleh sebuah lembaga swasta bernama Yayasan Pusaka Nias. 
Museum Pusaka Nias didirikan atas prakarsa Ordo Propinsi Kapusin Sibolga yang juga memiliki tugas dan fungsi untuk memelihara, melestarikan, dan mengembangkan nilai-nilai budaya yang tinggi dan luhur setiap suku bangsa di dunia.

Untuk itu, Yayasan Pusaka Nias mendirikan sejumlah gedung untuk memperlancar operasional museum. Salah satu syarat sebuah museum adalah bangunannya yang dapat berupa bangunan baru atau memanfaatkan gedung lama. Harus memenuhi prinsip-prinsip konservasi, agar koleksi museum tetap lestari. Bangunan museum minimal dapat dikelompok menjadi dua kelompok, yaitu bangunan pokok (pameran tetap, pameran temporer, auditorium, kantor, laboratorium konservasi, perpustakaan, bengkel preparasi, dan ruang penyimpanan koleksi) dan bangunan penunjang (pos keamanan, museum shop, tiket box, toilet, lobby, dan tempat parker). Sehubungan dengan ketentuan tersebut dan sesuai dengan hasil observasi peneliti, maka Museum Pusaka Nias telah memiliki standar sebuah museum yang baik yang memiliki sarana dan prasarana yang lengkap dalam menunjang operasional museum.

Gedung pameran Museum Pusaka Nias terdiri dari empat paviliun. Beberapa gedung penunjang sebagai kantor operasional, tempat miniatur rumah-rumah tradisional, balai pertemuan (omo bale), rumah tamu, halaman batu-batu megalit, gedung perkantoran (tata usaha), gedung reparasi/perawatan, gedung pameran tematis, perpustakaan, dan kantin. Selain itu juga tersedia tempat parkir bagi pengunjung. Sejumlah toilet bagi pengunjung dilokasi yang berbeda diantaranya di samping gedung pameran benda pusaka dan disamping kantin.

Pastor Johannes berkata bahwa sarana dan prasarana diatas belumlah cukup untuk menarik minat dan perhatian masyarakat untuk datang berkunjung ke museum. Sebab masyarakat saat ini memiliki minat yang sangat minim terhadap benda-benda pusaka yang ada di dalam gedung pameran. Maka, untuk menarik perhatian masyarakat datang berkunjung. diatas lahan seluas dua hektar dibangun beberapa wahana yang menarik. Wahana tersebut diantaranya taman mini flora dan fauna. Jenis flora yang terdapat di taman tersebut adalah tanaman yang sudah sangat langka ditemukan di Pulau Nias dan berbau mistis/religius serta bisa menjadi ramuan obat tradisional Nias, 
seperti pohon Amandraya, pohon Fösi, pohon Ohulu, pohon Boli, Sirih, tumbuhan Ladari, tumbuhan Endruo (Andong), tumbuhan Woyowoyo (Kecombrang), dan tumbuhan Zini-zini (Cocor Bebek). Sedangkan jenis fauna yang terdapat ditaman mini tersebut adalah binatang-binatang yang keberadaannya sudah langka dan yang ada hubungannya dengan mite-mite atau dongeng dan sering dilukiskan sebagai simbol untuk mengekspresikan suatu idea, seperti Ular, Buaya, Kancil, Monyet, Biawak, Kura-kura, Kijang, burung Beo, burung Enggang, burung Tekukur (Anduhur), burung Nazase, burung Siliwi, Landak, Musang, Kalong, Babi Hutan, Rusa, dan Kancil.

Untuk lebih menarik perhatian dan minat semua kalangan masyarakat, mulai dari anak-anak sampai orang tua, kompleks Museum Pusaka Nias yang langsung berbatasan dengan lautan Hindia, dirancang pemandian mini yang nyaman bagi pengunjung. Dan yang terakhir adalah gedung asrama yang diperuntukkan bagi karyawan yang bekerja di Museum Pusaka Nias dan bagi siswa/siswi yang bersekolah di sekitaran Gunungsitoli.

Keberadaan sarana dan prasarana tersebut telah mampu menarik perhatian dan minat para pengunjung yang sedang melakukan liburan maupun sedang ingin berekreasi. Tentu hal tersebut menjadi keuntungan bagi keberlangsungan museum untuk terus beroperasi dengan baik.

\section{Benda-Benda Pusaka Koleksi Museum Pusaka Nias}

Seluruh benda-benda pusaka koleksi Museum Pusaka Nias yang telah terinventarisasi disusun dan dipamerkan dalam sebuah gedung yang terdiri dari empat paviliun dan satu ruang tengah. Penempatan benda-benda tersebut disusun sedemikian rupa agar terlihat rapi dan menarik. Pada bagian ini, peneliti mengelompokkan bendabenda koleksi berdasarkan ruangan atau paviliun tempat benda-benda koleksi tersebut dipamerkan. Berikut ini akan diuraikan benda-benda koleksi Museum Pusaka Nias berdasarakan paviliun atau ruang pameran benda-benda koleksi. 


\section{Paviliun I}

Paviliun I merupakan ruang pameran pertama yang dimasuki setiap pengunjung yang ingin melihat benda-benda pusaka Nias. Menyajikan berbagai artefak sebagai bukti material yang menggambarkan keagungan seorang Ono Niha pada masa lalu mulai dari kehidupannya secara pribadi, dalam keluarga, dalam masyarakat hingga ke sisi religius yang berkaitan dengan dunia dan kepercayaannya. Artefak-artefak tersebut berkaitan juga dengan dimensi kehidupan yang agung (Molakhomi) dan terhomat (mosumange) dan tegas/keras (mosofu). Hal tersebut tercermin melalui Perhiasan bangsawan laki-laki (gama-gama ndra matua), perhiasan bangsawan perempuan (gama-gama ndra'alawe), perhiasan pengantin perempuan, pakaian dan senjata perang, pedang (tolögu), belati (ekhe), tombak (toho), mata tombak berkait (toho sondrami) dan tidak berkait (burusa), patung harimau (adu harimao), adu siraha horö, omo hada (rumah adat), talumbaho, omo hada (rumah adat) nifolasara, rumah balai (omo bale), tamburu (tambur), aramba (gong), fondrahi (tambur), tempat sirih (naha nafo), dan juga buku-buku yang telah diterbitkan oleh Yayasan Pusaka Nias, serta beberapa cenderamata khas Museum Pusaka Nias.

\section{Paviliun II}

Paviliun II merupakan ruang pameran kedua. Ruangan ini menyajikan berbagai rangkaian persta dan upacara owasa. Di ruangan ini pengunjung dapat menyaksikan berbagai peralatan hidup yang dipakai dalam aktifitas keseharian. Seperti osa-osa (usungan), mikrolit ni'omanu-manu, wadah perhiasan (naha gamagama), peralatan rumah tangga, takaran, alat-alat ukur, keramik dari china, pakaian dari serat tumbuhtumbuhan, pakaian dari serat kulit kayu ohulu, pakaian perang dari lempeng besi, tameng (baluse rene), patung ( $a d u)$ sarambia, patung (adu) inada larise, takula, peti berdiri (hasi nifedadao), kursi jenazah (sarambia), sarkofagus, peti mati (hasi) nifolasara. 


\section{Paviliun III}

Paviliun III menyajikan karya seni hasil aktifitas keseharian masyarakat Nias dulu. Terdapat berbagai miniatur rumah adat, perabotan rumah tangga, alat pemeras sari tebu (folazi döwu), alat-alat pertanian, peralatan tukang, benda-benda kesaktian, alat penerangan, alat musik tradisional nias, peralatan dapur, alat tangkap dan berburu, anyaman tikar dan selimut, ukiran dinding altar raja, ukiran dinding laso so hagu, ukiran dinding perahu dan ikan, patung leluhur (adu nuwu, adu zatua, dan siraha salawa), ukiran kayu biatang liar (adu utu ndru'u).

\section{Paviliun IV}

Paviliun IV merupakan ruang pameran foto "Lompatan Budaya Nias 100 Tahun Lalu dan Kini". Diisi dengan foto-foto para penginjil/evangelish yang pernah bertugas di Pulau Nias. Mulai dari missionaris Gereja Katolik bernama Jean Pierre Vallon. Kemudian disusul oleh Pastor Jean Laurent Berard pada tahun 1832. Mereka meninggal tidak lama setelah berada di Pulau Nias, di pulau yang terkenal dengan para pemenggal kepala manusia, lahan malaria, bumi ilmu hitam, dll. Begitu juga dengan Pastor Caspar de Hesselle, ia wafat seketika tiiba di Pulau Nias. Setelah itu terjadi kekosongan misi Gereja Katolik hingga tahun 1939 (107 Tahun). Baru pada tahun 1939, Pastor Burchardus van der Weijden diberi ijin masuk ke Pulau Nias oleh pemerintah Hindia Belanda.

Kemudian tahun 1865, missionaris RMG dari Jerman bernama Ernst Ludwig Denninger masuk ke Pulau Nias. Ia berhasil mengabarkan injil. Sejak saat itu, semakin banyak jumlah orang Nias yang dibabtis. Mulai 1865 sampai 1939 misionaris gereja Kristen Prostestan berjaya di Pulau Nias. Namun gereja otonomi yang bernama BNKP (Banua Niha Keriso Protestan) baru disahkan dalam sinode pertama pada tahun 1939. Perlu diketahui bahwa pemilihan Lowolangi (salah satu dewa yang dimiliki suku Nias) untuk menyebut nama Tuhan dilakukan oleh E. L. Denninger. 


\section{Ruang Tengah}

Ruang tengah merupakan ruang pameran benda-benda megalith. Benda megalith yang terdapat dalam ruang tengah antara lain meja-meja batu, patung-patung usungan (osa-osa), patung-patung ayam (ni'omanu-manu), dan patung leluhur (adu Lawölö).

Jika osa-osa merupakan patung yang digunakan dalam upacara adat owasa untuk menaikkan status seseorang dalam masyarakat dan patung ni'omanu-manu menjadi simbol dari status atau kedudukan seseorang yang tinggi dalam masyarakat, maka berbeda dengan adu Lawölö. Adu Lawölö merupakan patung leluhur yang dipercaya dapat melindungi masyarakat dari pengaruh jahat. Terkhusus saat warga desa ingin melakukan peperangan, maka mereka terlebih dahulu meminta perlindungan kepada adu Lawölö. Selain untuk berperang, adu Lawölö juga diletakkan di pintu gerbang desa untuk menangkal segala kekuatan jahat yang akan masuk ke dalam desa.

\section{Sistem Pengadaan Koleksi Museum Pusaka Nias}

Koleksi museum merupakan bahan atau obyek penelitian ilmiah. Museum bertugas mengadakan, melengkapi dan mengembangkan tersedianya obyek penelitian ilmiah itu bagi siapapun yang membutuhkan. Dalam menentukan kebijakan pengadaan koleksi perlu mempertimbangkan hal-hal berikut:

A. Prinsip dan persyaratan sebuah benda menjadi koleksi, antara lain:

1. Memiliki nilai sejarah dan nilai ilmiah (termasuk nilai estetika);

2. Dapat diidentifikasikan mengenai bentuk, tipe, gaya, fungsi, makna, asal secara historis dan geografis, genus (untuk biologis), atau periodenya (dalam geologi, khususnya untuk benda alam);

3. Harus dapat dijadikan dokumen, dalam arti sebagai bukti kenyataan dan eksistensinya bagi penelitian ilmiah

B. Pertimbangan skala prioritas, yaitu penilaian untuk benda-benda yang bersifat:

1. Masterpiece, merupakan benda yang terbaik mutunya 
2. Unik, merupakan benda-benda yang memiliki ciri khas tertentu bila dibandingkan dengan benda-benda yang sejenis

3. Hampir punah, merupakan benda yang sulit ditemukan karena dalam jangka waktu yang sudah terlalu lama tidak dibuat lagi

4. Langka, merupakan benda-benda yang sulit ditemukan karena tidak dibuat lagi atau karena jumlah hasil pembuatannya hanya sedikit.

Pengadaan merupakan suatu kegiatan pengumpulan (collecting) berbagai benda yang akan dijadikan koleksi museum, baik berupa benda asli (realia) ataupun tidak asli (replika). Pengadaan koleksi dapat dilakukan dengan cara:

(1) Hibah (hadiah atau sumbangan);

(2) Titipan;

(3) Pinjaman;

(4) Tukar menukar dengan museum lain;

(5) Hasil temuan (dari hasil survei, ekskavasi, atau sitaan); dan

(6) Imbalan jasa (pembelian dari hasil penemuan atau warisan).

Berdasarkan informasi diatas, maka perolehan koleksi museum pusaka Nias adalah :

\begin{tabular}{|c|l|c|}
\hline No & Status Kepemilikan & Jumlah \\
\hline 1 & Hibah & 947 \\
\hline 2 & Titipan & 9 \\
\hline 3 & Pinjaman & - \\
\hline 4 & Tukar-menukar & - \\
\hline 5 & Hasil Temuan & 5045 \\
\hline 6 & Imbalan Jasa & $\mathbf{6 0 0 1}$ \\
\hline & Total & \\
\hline
\end{tabular}

Tabel 1. Data status perolehan koleksi museum 2015 Sumber : Museum Pusaka Nias 
Dari tabel diatas, dapat kita lihat bahwa sebagian besar benda koleksi diperoleh melalui imbalan jasa atau dengan istilah lain dibeli, yaitu sebesar $84 \%$. Selebihnya adalah melalui hibah dan titipan. Sedangkan yang pinjaman, tukar-menukar dengan museum lain, dan hasil temuan museum itu sendiri tidak ada sama sekali.

Benda-benda koleksi tersebut dikumpulkan dari seluruh bagian daerah pemerintahan yang ada di Pulau Nias, yaitu Nias Selatan, Nias Tengah, Nias Barat, Nias Kota, dan Nias Utara. Beberapa benda koleksi didatangkan dari luar negeri. Pada tahun 2006, sebuah rompi yang terbuat dari kulit buaya milik keluarga Horst Krank (mantan missionaris VEM) dipulangkan setelah sekitar 35 tahun berada di Eropa. Pada tahun 2008, artefak berupa manik-manik khas Nias berhasil dipulangkan. Pada tahun 2009, sebanyak 30 artefak berhasil dikembalikan dari sebuah Universitas di negara Belanda. Terakhir, seorang kolektor bernama Helmut Paasch di Jakarta, dengan penuh kerelaan mengembalikan sejumlah perhiasan yang terbuat dari emas.

\section{E. Sistem Klasifikasi Koleksi di Museum Pusaka Nias}

Klasifikasi merupakan pengelompokan koleksi berdasarkan kriteria tertentu, yaitu menurut disiplin ilmu, subdisiplin ilmu, serta berdasarkan jenis, bahan, asal daerah, dan kronologi. Tujuan klasifikasi adalah untuk menciptakan pengelompokan dan mempermudah dalam pengelolaan dan penelitian koleksi sehingga dapat dimanfaatkan secara optimal untuk kepentingan pendidikan, studi, dan rekreasi.

Maka dari keseluruhan koleksi Museum Pusaka Nias yang berada di ruang pameran dan berdasarkan keterangan yang diberikan pengelola museum, benda-benda koleksi tersebut diklasifikasikan berdasarkan disiplin ilmu, seperti tabel ini:

\begin{tabular}{|c|l|c|}
\hline No & Klasifikasi (Disiplin Ilmu) & Jumlah \\
\hline 1 & Etnografi & 4828 \\
\hline 2 & Geologika & 116 \\
\hline 3 & Biologika & 260 \\
\hline
\end{tabular}




\begin{tabular}{|c|l|c|}
\hline 4 & Historika & 568 \\
\hline 5 & Arkeologika & 27 \\
\hline 6 & Numismatika & 10 \\
\hline 7 & Keramologika & 190 \\
\hline 8 & Seni rupa & 2 \\
\hline \multicolumn{2}{|c|}{ Total } & $\mathbf{6 0 0 1}$ \\
\hline
\end{tabular}

Tabel 2. Data klasifikasi koleksi museum 2015

Sumber : Museum Pusaka Nias

Dari tabel diatas, dapat kita lihat bahwa mayoritas benda koleksi tergolong kepada Etnografi (80\%). Artinya benda-benda koleksi tersebut mencerminkan ciri-ciri sebuah ras yang dalam hal ini adalah suku Nias.

Untuk lebih memahami jenis koleksi Museum Pusaka Nias, dibawah ini disebutkan beberapa contoh benda sesuai dengan klasifikasinya.

1. Etnografika, seperti adu zatua/patung leluhur yaitu atung yang dibuat untuk mengenang orang tua yang sudah meninggal

2. Geografika/Geologika, seperti Sikhori lafau (batuan) artinya batu sungai yang menurut mitos dimana batu ini terdapat maka tanah disekitarnya tidak akan kena longsor dan beberapa batuan yang didapat dari sungai seperti batu akik yang merupakan golongan klasifikasi Geografika/Geologika

3. Biologika, seperti Tanduk Rusa yang digunakan sebagai hiasan dinding rumah adat dan sekaligus berfungsi sebagai gantungan

4. Historika, seperti Osa-osa Ni'oböhö si Sambua hōgō (batu megalitik) usungan berkepala Rusa yang digunakan sebagai usungan bangsawan saat mengadakan pesta Owasa.

5. Arkeologika, seperti Fana Maria/Meriam yaitu peninggalan Belanda pada masa penjajahan sewaktu belanda menduduki daerah Sumatra - Nias

6. Numismatika/Heraldika, seperti mata uang kuno Nias, "öri" yang digunakan sebagai alat tukar membeli barang 
7. Keramologika, seperti sepatu yang terbuat dari tampi kelapa sebagai alas kaki

8. Seni rupa, seperti lukisan air terjun Helaowo Sidele Gi'a di kecamatan Gomo

Aturan dalam menyusun benda-benda di dalam ruang pameran dalam sebuah museum adalah :

1. Melihat dan memperhatikan lokasi pameran

2. Tata letak penyusunan seperti jarak pandang, penulisan label/keterangan koleksi, keamanan koleksi

3. Memperhatikan sistematika koleksi.

Oleh sebab itu, benda-benda koleksi dalam museum tidak harus disusun sesuai dengan klasifikasinya. Benda-benda koleksi disusun seefektif mungkin dalam ruangan supaya terlihat menarik, rapi, dan teratur.

\section{PENUTUP}

Melalui hasil penelitian dan pembahasan yang telah diuraikan serta mengacu pada rumusan masalah, maka benda-benda bersejarah yang menjadi koleksi di Museum Pusaka Nias adalah Perhiasan bangsawan laki-laki (gama-gama ndra matua), perhiasan bangsawan perempuan (gama-gama ndra'alawe), perhiasan pengantin perempuan, pakaian dan senjata perang, pedang (tolögu), belati (ekhe), tombak (toho), mata tombak berkait (toho sondrami) dan tidak berkait (burusa), patung harimau ( $a d u$ harimao), adu siraha horö, omo hada (rumah adat), talumbaho, omo hada (rumah adat) nifolasara, rumah balai (omo bale), tamburu (tambur), aramba (gong), fondrahi (tambur), tempat sirih (naha nafo), osa-osa (usungan), mikrolit ni'omanu-manu, wadah perhiasan (naha gamagama), peralatan rumah tangga, takaran, alat-alat ukur, keramik dari china, pakaian dari serat tumbuh-tumbuhan, pakaian dari serat kulit kayu ohulu, pakaian perang dari lempeng besi, tameng (baluse rene), patung (adu) sarambia, patung (adu) inada larise, takula, peti berdiri (hasi nifedadao), kursi jenazah (sarambia), sarkofagus, peti mati (hasi) nifolasara, miniatur rumah adat, perabotan rumah tangga, alat pemeras sari tebu (folazi döwu), alat-alat pertanian, peralatan tukang, benda-benda kesaktian, alat penerangan, alat musik tradisional nias, peralatan 
dapur, alat tangkap dan berburu, anyaman tikar dan selimut, ukiran dinding altar raja, ukiran dinding laso so hagu, ukiran dinding perahu dan ikan, patung leluhur (adu nuwu, adu zatua, dan siraha salawa), ukiran kayu biatang liar (adu utu ndru'u), dan patung (adu) lawölö. Benda-benda bersejarah koleksi Museum Pusaka Nias diklasifikasikan berdasarkan bidang/disiplin ilmu, yaitu Etnografi, Geologika, Biologika, Historika, Arkeologika, Numismatika (mata uang), Keramologika, dan Seni Rupa. Benda-benda bersejarah koleksi Museum Pusaka Nias diperoleh melalui hibah atau disumbangkan, ada yang dititipkan, dan mayoritas melalui imbalan jasa atau ganti rugi atau dibeli.

\section{DAFTAR REFERENSI}

Adrianus Gulo. Museum Budaya di Nias., 050112278

Forniha. (2010). Membangun Daya Organisasi Masyarakat Sipil Bersama Forniha. Nias : Forniha

Hämmerle, P. Johannes M. OFM Cap. (2013). Pasukan Belanda di Kampung Para Penjagal (Terjemahan). Gunungsitoli : Yayasan Pusaka Nias

Koestoro, Lucas Partanda dan Ketut Wiradnyana. (2007). Tradisi Megalitik di Pulau Nias. Medan : Balai Arkeologi Medan

Meuraxa, Dada. (1973). Sejarah Kebudayaan Suku-Suku di Sumatera Utara. Medan : Saterawan Samping Kiri Dalam Stasiun Bus Teladan 250 A Medan

Museum Nusantara. (1990). Nias, Tribal Treasures. Delft : Vokenkundig Museum Nusantara

Museum Pusaka Nias. (2008). Katalog Koleksi-Museum Pusaka Nias. Nias : Museum Pusaka Nias

Yayasan Pusaka Nias. (2011). Ensiklopedia Pusaka Pulau Nias. Nias : PNPM-R2PN

Yayasan Pusaka Nias. (2011). Katalog Koleksi-Museum Pusaka Nias Paviliun II. Nias : PNPM-R2PN

Zebua, Viktor. (2010). Jejak Cerita Rakyat Nias. Yogjakarta : Posko Delasiga dan Pustaka Pelajar 